Article

\title{
Dendropanoxide, a Triterpenoid from Dendropanax morbifera, Ameliorates Hepatic Fibrosis by Inhibiting Activation of Hepatic Stellate Cells through Autophagy Inhibition
}

\author{
Yong-Joo Park ${ }^{1,+}$, Dong-Min Kim ${ }^{2,3,+}$, Hye-Been Choi ${ }^{2}$, Mi-Ho Jeong ${ }^{4}$, Seung-Hwan Kwon ${ }^{5}$, Ha-Ryong Kim ${ }^{6}$, \\ Jong-Hwan Kwak ${ }^{2, * \mathbb{D}}$ and Kyu-Hyuck Chung ${ }^{2, *}$ \\ 1 College of Pharmacy, Kyungsung University, Busan 48434, Korea; yjpark@ks.ac.kr \\ 2 School of Pharmacy, Sungkyunkwan University, Suwon 16419, Korea; kdm9947@gmail.com (D.-M.K.); \\ ly0412b@skku.edu (H.-B.C.) \\ 3 New Drug Research Center, Handok Inc., Seoul 06235, Korea \\ 4 Center for Systems Biology, Massachusetts General Hospital, Boston, MA 02114, USA; algh8906@naver.com \\ 5 Department of Neurology, Johns Hopkins University School of Medicine, Baltimore, MD 21205, USA; \\ kwon4862@naver.com \\ 6 College of Pharmacy, Daegu Catholic University, Gyeongsan 38430, Korea; kimhr@cu.ac.kr \\ * Correspondence: jhkwak@skku.edu (J.-H.K.); khchung@skku.edu (K.-H.C.) \\ + These authors contributed equally to this work.
}

Citation: Park, Y.-J.; Kim, D.-M.; Choi, H.-B.; Jeong, M.-H.; Kwon,

S.-H.; Kim, H.-R.; Kwak, J.-H.; Chung,

K.-H. Dendropanoxide, a

Triterpenoid from Dendropanax morbifera, Ameliorates Hepatic

Fibrosis by Inhibiting Activation of

Hepatic Stellate Cells through

Autophagy Inhibition. Nutrients 2022,

14, 98. https://doi.org/10.3390/

nu14010098

Academic Editor: Anna Alisi

Received: 19 November 2021

Accepted: 23 December 2021

Published: 27 December 2021

Publisher's Note: MDPI stays neutral with regard to jurisdictional claims in published maps and institutional affiliations.

Copyright: (C) 2021 by the authors. Licensee MDPI, Basel, Switzerland. This article is an open access article distributed under the terms and conditions of the Creative Commons Attribution (CC BY) license (https:// creativecommons.org/licenses/by/ $4.0 /)$.

\begin{abstract}
Hepatic fibrosis results from chronic liver damage and is characterized by excessive accumulation of extracellular matrix (ECM). In this study, we showed that dendropanoxide (DPX), isolated from Dendropanax morbifera, had anti-fibrotic effects on hepatic fibrosis by inhibiting hepatic stellate cell (HSC) activation. DPX suppressed mRNA and protein expression of $\alpha$-SMA, fibronectin, and collagen in activated HSCs. Moreover, DPX $(40 \mathrm{mg} / \mathrm{kg})$ treatment significantly lowered levels of liver injury markers (aspartate aminotransferase and alanine transaminase), expression of fibrotic markers, and deposition of ECM in a carbon tetrachloride-induced mouse model. Anti-fibrotic effects of DPX were comparable to those of silymarin in a hepatic fibrosis mouse model. As a possible mechanism of anti-fibrotic effects, we showed that DPX inhibited autophagosome formation (LC3B-II) and degradation of p62, which have important roles in HSC activation. These findings suggest that DPX inhibits HSC activation by inhibiting autophagy and can be utilized in hepatic fibrosis therapy.
\end{abstract}

Keywords: dendropanoxide; hepatic fibrosis; hepatic stellate cells; autophagy; carbon tetrachloride

\section{Introduction}

Hepatic fibrosis is a chronic liver disease characterized by increased production and deposition of extracellular matrix (ECM) and is a global health burden [1]. Hepatic fibrogenesis is a dynamic process that can lead to disruption of the normal cellular function of the liver [2]. During hepatic fibrogenesis, hepatic stellate cells (HSCs), portal myofibroblasts, and immune cells are important in ECM production in response to liver injury. HSC activation is a key event in hepatic fibrogenesis and is responsible for about $80 \%$ of total fibrillar collagens in the fibrotic liver $[3,4]$.

HSC account for 5-10\% of all hepatic cells, are present in the perisinusoidal space of Disse, and store vitamin A under normal healthy conditions [5]. Hepatic injury transforms HSC s to myofibroblast-like cells that show proliferative, contractile, and migratory properties and secrete pro-inflammatory and pro-fibrotic mediators [5]. Alpha-smooth muscle actin ( $\alpha$-SMA) is a specific marker for activated HSCs, and increased $\alpha$-SMApositive cells are observed in hepatic fibrosis patients [6-9]. Therefore, inhibition of HSC activation has been considered an important strategy in the development of drugs for hepatic fibrosis $[5,10]$. Autophagy is a catabolism process that has cell-specific roles during chronic liver diseases [11]. In HSC, autophagy promotes fibrogenic properties and collagen 
accumulation; therefore, autophagy inhibition in HSCs can be a therapeutic target for hepatic fibrosis [12].

Dendropanax morbifera Léveille (DPM), a subtropical evergreen tree belonging to the family Araliaceae, is distributed and cultivated in the southern regions of South Korea [13]. DPM has been widely used as a traditional medicine, and the Korea Food and Drug Administration (KFDA) has approved the leaf, stem, and root of DPM as a food ingredient $[13,14]$. DPM has anti-oxidant [14,15], anti-inflammatory [16,17], anti-diabetic [18,19], and antiatherogenic properties [20]. The aqueous extract of DPM was recently shown to prevent thioacetamide-induced hepatoxicity and oxidative stress in rats, but the anti-fibrotic effects of DPM components have not been investigated in detail [21].

In this study, we aimed to discover an anti-fibrotic agent for hepatic fibrosis by inhibiting HSC activation. Dendropanoxide (DPX) was isolated from the ethanolic extract of DPM, and its anti-fibrotic effect was analyzed in activated LX-2 human hepatic stellate cells and a carbon-tetrachloride-induced hepatic fibrosis mouse model. The molecular mechanisms of DPX were explored, and we evaluated the therapeutic potential of DPX based on anti-fibrotic effects.

\section{Materials and Methods}

\subsection{Extraction and Isolation of DPX}

Aerial parts of D. morbifera were collected in February 2019 from a farm in Goheunggun, Jellanam-do, Korea $\left(34^{\circ} 48^{\prime} 05^{\prime \prime} \mathrm{N}\right.$ and $\left.127^{\circ} 18^{\prime} 06^{\prime \prime} \mathrm{E}\right)$. The plant was identified by author Dr. J.H. Kwak, a specialist in plant taxonomy. A voucher specimen (specimen No.: SKKU-Ph-19-002) was deposited at the Herbarium of School of Pharmacy, Sungkyunkwan University. The dried aerial parts of DPM $(2 \mathrm{~kg})$ were extracted twice in $95 \%$ ethanol (8 L) at $18-22{ }^{\circ} \mathrm{C}$ for $24 \mathrm{~h}$ and then once at $60{ }^{\circ} \mathrm{C}$ for $5 \mathrm{~h}$. The total filtrate was concentrated under reduced pressure at $40{ }^{\circ} \mathrm{C}$ to obtain an ethanolic extract. This extract $(73.57 \mathrm{~g})$ was suspended in distilled water $(0.9 \mathrm{~L})$ and successively partitioned with dichloromethane $\left(\mathrm{CH}_{2} \mathrm{Cl}_{2}\right)$, ethyl acetate (EtOAc), and n-butanol (n-BuOH) to give $\mathrm{CH}_{2} \mathrm{Cl}_{2}(19.03 \mathrm{~g})$, EtOAc $(2.91 \mathrm{~g}), \mathrm{n}-\mathrm{BuOH}(6.50 \mathrm{~g})$, and water $(57.05 \mathrm{~g})$ fractions. A portion $(8.3 \mathrm{~g})$ of the $\mathrm{CH}_{2} \mathrm{Cl}_{2}$ fraction was subjected to silica gel column chromatography $(5 \times 42 \mathrm{~cm})$ using a stepwise elution with hexane- $\mathrm{CH}_{2} \mathrm{Cl}_{2}$ (10:1-5:1-3:1-1:1, v/v; $500 \mathrm{~mL}$ for each solvent mixture), $\mathrm{CH}_{2} \mathrm{Cl}_{2}$ only (500 mL), $\mathrm{CH}_{2} \mathrm{Cl}_{2}-\mathrm{MeOH}$ (50:1-10:1-1:1, v/v; $500 \mathrm{~mL}$ for each solvent mixture), and $\mathrm{MeOH}$ only ( $1 \mathrm{~L}$ ) to yield 9 fractions (F1-F9). The F3 fraction (hexane- $\mathrm{CH}_{2} \mathrm{Cl}_{2}=3: 1$ fraction, $952 \mathrm{mg})$ was twice chromatographed over silica gel columns $(3 \mathrm{~cm} \times 40 \mathrm{~cm})$ using hexane- $\mathrm{CH}_{2} \mathrm{Cl}_{2}$ solvent mixtures (3:1 and 1:1, respectively) to obtain a white crude compound $(806 \mathrm{mg})$. The crude compound was further purified by recrystallization using the $\mathrm{CH}_{2} \mathrm{Cl}_{2}-\mathrm{MeOH}$ solvent mixture (1:3, $v / v$ ) to afford DPX (735 mg; Rf: $0.22, \mathrm{SiO}_{2}$, hexaneEtOAc $=5: 1, v / v, 10 \% \mathrm{H}_{2} \mathrm{SO}_{4}$ in EtOH) at $97.6 \%$ purity by GC-MS analysis.

\subsection{Chemicals}

Transforming growth factor (TGF)- $\beta 1$ was obtained from R\&D Systems (\#240-B; Minneapolis, MN, USA), and chloroquine (\#C6628) and silymarin (\#S0292) were obtained from Sigma-Aldrich (St. Louis, MO, USA).

\subsection{Cell Lines and Culture}

LX-2 cells, immortalized human hepatic stellate cells, were obtained from the ATCC (Manassas, VA, USA), and 10\% fetal bovine serum (Biotechnics Research Inc., Lake Forest, CA, USA) with Dulbecco's Modified Eagle's Medium (Sigma) was used to support cell growth. Cells were maintained at $37^{\circ} \mathrm{C}$ in an atmosphere $\left(95 \%\right.$ air and $\left.5 \% \mathrm{CO}_{2}\right)$ under saturation humidity.

\subsection{Animal Experiments}

Animal experiments were approved by the Sungkyunkwan University Animal Care Committee (SKKUIACUC2018-10-44-2). Six-week-old male C57BL/ 6 mice (22-25 g) were 
purchased from Daehan BioLink (Chungbuk, Korea). After acclimatization for one week, the mice were randomly divided into six groups (seven mice per group) that received: (1) olive oil (vehicle control) and PBS; (2) carbon tetrachloride and PBS; (3), (4), (5) carbon tetrachloride and $\operatorname{DPX}(2,10,40 \mathrm{mg} / \mathrm{kg}$, respectively); and (6) carbon tetrachloride and silymarin $(40 \mathrm{mg} / \mathrm{kg})$. All chemicals were treated with intraperitoneal injection (I.P.). Mice were treated with carbon tetrachloride $(2 \mathrm{~mL} / \mathrm{kg})$ three times per week until experiment completion. After three weeks of carbon tetrachloride injection, mice were treated with PBS or DPX $(2,10,40 \mathrm{mg} / \mathrm{kg})$ or silymarin $(40 \mathrm{mg} / \mathrm{kg})$ three times per week for three weeks. On day 43 , mice were anesthetized with isoflurane and liver tissue, and blood samples were collected and stored at $-80^{\circ} \mathrm{C}$ before analysis.

\subsection{Liver Histology and Blood Analysis}

The formalin-fixed liver tissues were embedded in paraffin and cut into sections $(4 \mu \mathrm{m})$. Hematoxylin and eosin (H\&E) and Masson's trichrome stains were used for analysis. Twenty randomly selected images of each stained section were used for quantification. Alanine transaminase (ALT) and aspartate aminotransferase (AST) levels in mouse serum were analyzed by Beckman Coulter AU680 (Beckman Coulter, Brea, CA, USA) as a measure of liver function (ChemOn Inc. Suwon, Korea).

\subsection{Cell Viability Assay}

The WST-1 assay was used to assess cell viability (Roche, Mannheim, Germany). After placing LX-2 cells in 96-well plates $\left(1 \times 10^{4}\right.$ cells /well $)$ for $24 \mathrm{~h}$, cells were treated with DPM extract or DPX for $48 \mathrm{~h}$. After adding WST-1 reagent, cells were incubated for $30 \mathrm{~min}$ at $37^{\circ} \mathrm{C}$. The absorbance at $440 \mathrm{~nm}$ and $690 \mathrm{~nm}$ was measured using a microplate spectrophotometer for analysis (Molecular Devices, Sunnyvale, CA, USA).

\subsection{Comparative Quantitative Real-Time PCR ( $q R T-P C R)$}

TRIzol reagent was used to isolate total RNA (Life Technologies, Grand Island, NY, USA). After cDNA was synthesized by the High-Capacity cDNA Reverse Transcription System (Life Technologies), qRT-PCR was performed using SYBR ${ }^{\circledR}$ Premix Ex TaqTM (Life Technologies) and CFX96 Real-Time PCR System (Bio-Rad, Hercules, CA, USA). qRT-PCR was conducted using the primers listed in Table 1 (Bioneer, Daejeon, Korea). GAPDH was used to normalized mRNA expression levels.

Table 1. Lists of qRT-PCR primers.

\begin{tabular}{cccc}
\hline Gene & Species & Forward & Reverse \\
\hline$\alpha-S M A$ & Human & CTGGCATCGTGCTGGACTCT & GATCTCGGCCAGCCAGATC \\
Col $1 A 1$ & Human & GGCAACAGCCGCTTCACCTAC & GCGGGAGGACTTGGTGGTTTT \\
Col $3 A 1$ & Human & CACGGAAACACTGGTGGACAGATT & ATGCCAGCTGCACATCAAGGAC \\
Fibronectin & Human & CAGTGGGAGACCTCGAGAAG & TCCCTCGGAACATCAGAAAC \\
LC3B-II & Human & CGCACCTTCGAACAAGAG & CTCACCCTTGTATCGTTCTATTA \\
$\alpha-S M A$ & Mouse & GTTCAGTGGTGCCTCTGTCA & ACTGGGACGACATGGAAAAG \\
Col $1 A 1$ & Mouse & TTCGGACTAGACATTGG & GGGTTGTTCGTCTGTTTC \\
Col $3 A 1$ & Mouse & ACGTAGATGAATTGGGATGCAG & GGGTTGGGGCAGTCTAGTG \\
\hline
\end{tabular}

\subsection{Western Blot Analysis}

After placing LX-2 cells in 6-well plates $\left(5 \times 10^{4}\right.$ cells /well $)$ for $24 \mathrm{~h}$, chemicals were treated for $48 \mathrm{~h}$ after TGF- $\beta 1$ treatment $(48 \mathrm{~h}$ ). After washing with PBS, cells were lysed with radioimmunoprecipitation assay buffer (Thermo Scientific, Waltham, MA, USA) with a protease inhibitor cocktail (GenDEPOT, Barker, TX, USA). Protein samples were denatured and resolved by $10 \%$ or $8-16 \%$ gradient SDS-PAGE (Bio-Rad) and transferred to a polyvinylidene difluoride membrane (Bio-Rad). After blocking with skim milk, the membrane was incubated overnight with primary antibodies. After washing with TBS-T, membranes were incubated with secondary antibodies conjugated to horseradish perox- 
idase. To detect the protein bands, an enhanced chemiluminescence reagent (Bio-Rad) was used. The GAPDH band was used to normalize the relative expression of the protein of interest. Anti-fibronectin (ab2413, Abcam, MA, USA), anti-collagen 1 (ab138492), anti-alpha-SMA (ab5694, Abcam), anti-p-SMAD2 (\#3108, CST, Danvers, MA), anti-p-p38 (\#9211), anti-p-ERK (\#4370), anti-p-AKT (\#9271), anti- $\beta$-catenin (\#8480), anti-p62 (\#2775), anti-LC3B (\#8025), and anti-GAPDH (015-25473, Wako Pure Chemical Industries, Osaka, Japan) were used in Western blot analysis.

\subsection{Statistical Analysis}

The data were analyzed using GraphPad Prism version 7.00 (GraphPad Software Inc., San Diego, CA, USA). All experiments were performed at least three times. The data are expressed as mean \pm standard deviation (SD). The differences between the groups were evaluated by Duncan's post hoc test after one-way analysis of variance (ANOVA).

\section{Results}

\subsection{Effects of DPM Extract on Activated Hepatic Stellate Cells}

LX-2 cells were treated with nontoxic concentrations of DPM extract $(0-80 \mu \mathrm{g} / \mathrm{mL})$ for $48 \mathrm{~h}$ after TGF- $\beta 1$ pre-treatment $(2 \mathrm{ng} / \mathrm{mL}, 48 \mathrm{~h}$ ) (Figure $1 \mathrm{~A})$. TGF- $\beta 1$ was used to activate LX-2 cells, and expression of $\alpha$-SMA and collagen was measured by Western blotting. TGF- $\beta 1$ treatment increased $\alpha$-SMA and collagen protein expression, and DPM extract significantly inhibited their expression (Figure 1B).

A

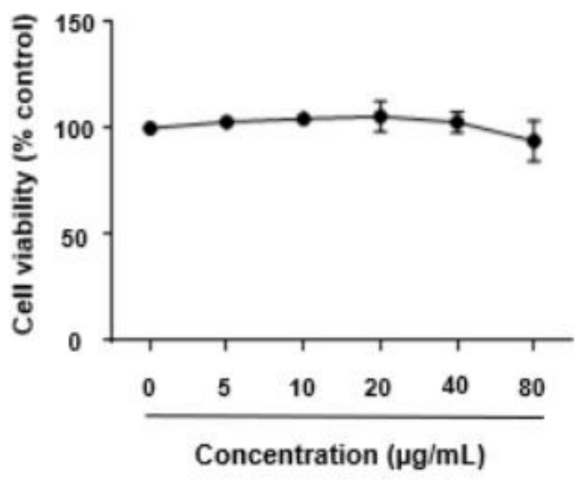

B

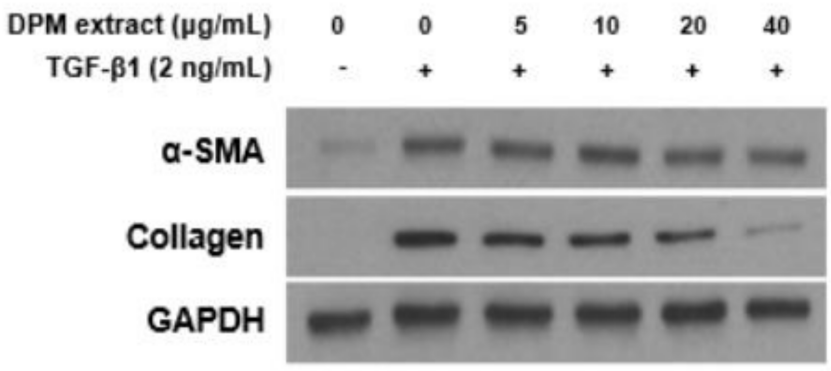

Figure 1. Dendropanoxide morbifera (DPM) ethanolic extract inhibited HSC activation and extracellular matrix (ECM) production in LX-2 cells. (A) Cytotoxicity was measured by the WST-1 assay after $48 \mathrm{~h}$ incubation with DPM extract. (B) $\alpha$-SMA and collagen protein expression levels were analyzed by Western blot assay. LX-2 cells were activated by incubation with $2 \mathrm{ng} / \mathrm{mL}$ transforming growth factor (TGF)- $\beta 1$ for $48 \mathrm{~h}$ and then treated with different concentrations of DPM extract for $48 \mathrm{~h}$. GAPDH was used as a loading control. Each experiment was repeated three times, and values represent mean $\pm \mathrm{SD}$.

\subsection{Isolation of DPX and Its Effects on Activated Hepatic Stellate Cells}

DPX (Figure 2) was obtained as a white solid from the dichloromethane fraction of DPM ethanolic extract. DPX was isolated and purified by repeated silica gel column chromatography with various solvent mixtures and recrystallization using the $\mathrm{CH}_{2} \mathrm{Cl}_{2}-\mathrm{MeOH}$ solvent mixture (Figure S1, Supporting Information). This compound exhibited spectroscopic data of ${ }^{1} \mathrm{H}$ NMR, ${ }^{13} \mathrm{C}$ NMR, and GC-MS (Figures S2-S4, Supporting Information) consistent with the literature values [22]. 


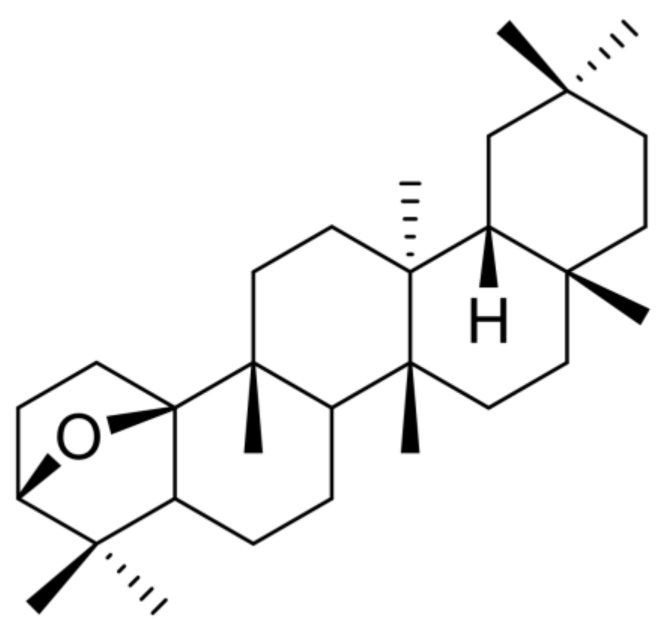

Figure 2. Chemical structure of dendropanoxide isolated from the ethanolic extract of DPM.

To determine the appropriate treatment concentration of DPX, cytotoxicity of various concentrations of DPX $(12.5-100 \mu \mathrm{g} / \mathrm{mL})$ was measured after incubation of the cells with DPX for $48 \mathrm{~h}$ (Figure 3A). To identify the inhibitory effects of DPX on HSC activation, 0.1-2 $\mu \mathrm{g} / \mathrm{mL}$ of DPX application for $48 \mathrm{~h}$ did not show cytotoxicity after activation by TGF- $\beta 1$. As shown in Figure 3B, protein expression of $\alpha$-SMA, fibronectin, and collagen was significantly increased after activation by TGF- $\beta 1$; however, DPX blocked this increase. Similarly, mRNA expression of $\alpha-S M A$, collagen $1 A 1$, collagen $3 A 1$, and fibronectin was alleviated by DPX in a concentration-dependent manner (Figure $3 C$ ).

A

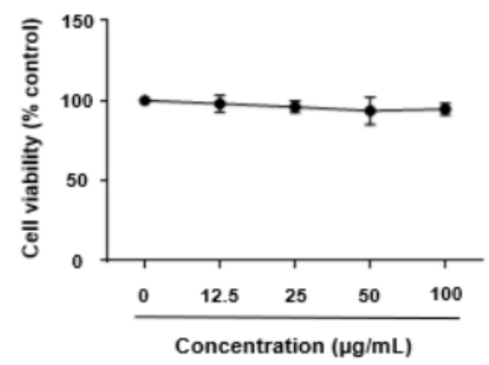

B

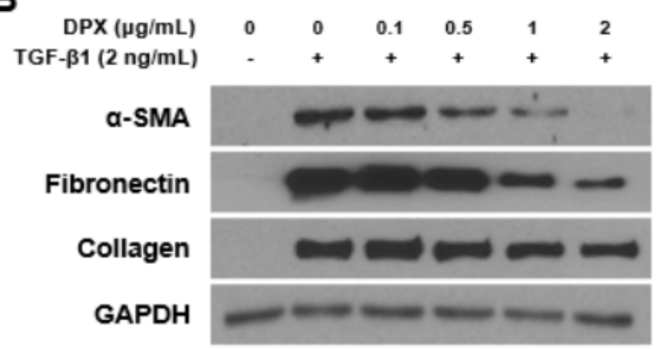

C

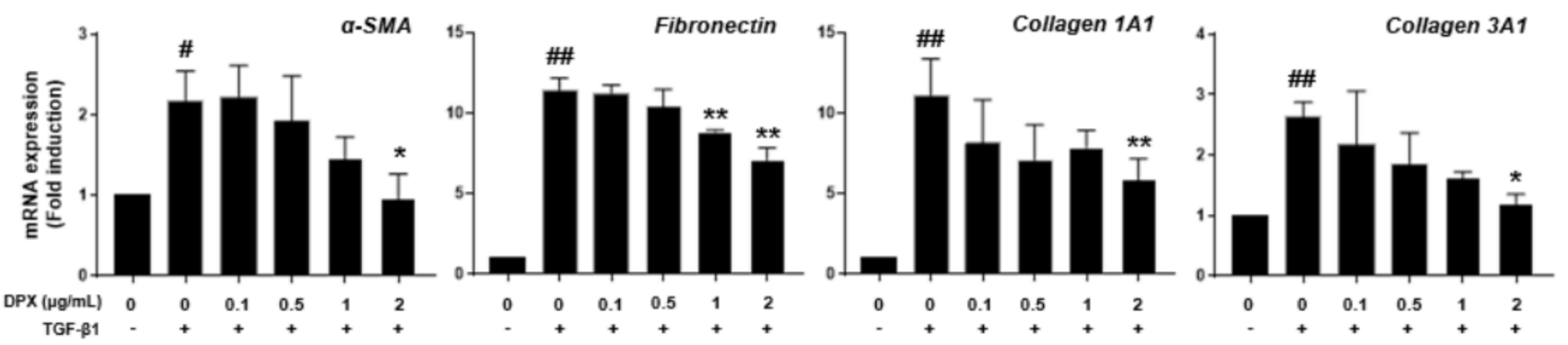

Figure 3. Dendropanoxide (DPX) inhibits HSC activation and collagen synthesis in LX-2 cells. (A) Cytotoxicity of DPX. Cytotoxicity was measured by WST-1 assay. (B) Protein expression of $\alpha$-SMA, fibronectin, and collagen was analyzed by Western blot assay. LX-2 cells were activated by $2 \mathrm{ng} / \mathrm{mL}$ TGF- $\beta 1$ for $48 \mathrm{~h}$ and then treated with different concentrations of DPX. GAPDH was used as a loading control. (C) Relative $\alpha$-SMA, fibronectin, collagen 1A1, and collagen $3 A 1$ mRNA expression was analyzed by qRT-PCR analysis. Each experiment was repeated three times, and values represent mean \pm SD. \# $p<0.05$, \#\# $p<0.01$ compared with control, ${ }^{*} p<0.05,{ }^{* *} p<0.01$ compared with the TGF- $\beta 1$ treatment group. 


\subsection{Anti-Fibrotic Effects of DPX in Hepatic Fibrosis Mice}

We performed the experiment with a carbon tetrachloride-induced hepatic fibrosis mouse model to test the effects of DPX on hepatic fibrosis. As shown in Figure 4A, DPX $(2,10$, and $40 \mathrm{mg} / \mathrm{kg})$ was administered intraperitoneally for three weeks at three weeks of carbon tetrachloride I.P. injection. Silymarin $(40 \mathrm{mg} / \mathrm{kg})$ was administered as a positive control. Body and liver weights were measured before and after treatments (Table 2). Liver and body weights were significantly increased by carbon tetrachloride treatment but were decreased by DPX $(40 \mathrm{mg} / \mathrm{kg})$ and silymarin treatment. Blood was collected at the end of the experiment to assess liver enzyme levels, and AST and ALT serum levels were significantly suppressed by DPX (10 and $40 \mathrm{mg} / \mathrm{kg}$ ) and silymarin treatment (Figure 4B). Gene expression of the fibrotic markers $\alpha-S M A$, collagen $1 A 1$, and collagen $3 A 1$ was significantly down-regulated in the carbon tetrachloride + DPX (10 and $40 \mathrm{mg} / \mathrm{kg})$-treated groups compared with carbon tetrachloride + PBS-treated group (Figure 4C). Similarly, the protein expression of fibronectin and $\alpha$-SMA was strongly suppressed by DPX injection (Figure 4D). Moreover, H \& E and Masson's trichrome staining showed a clear reduction in collagen deposition (Figure 4E).

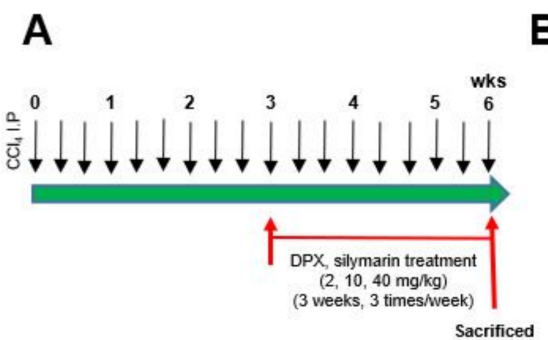

B

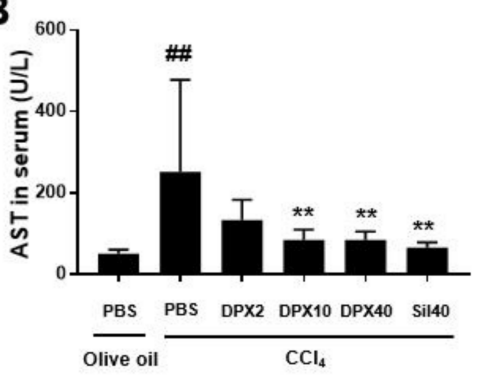

C

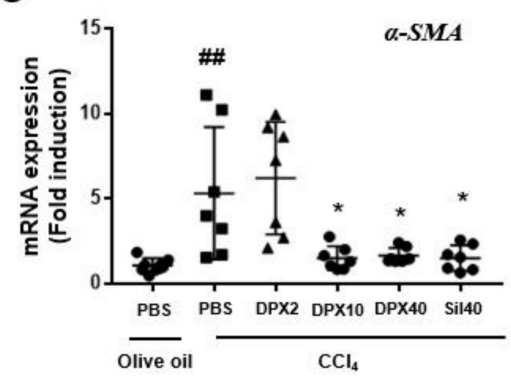

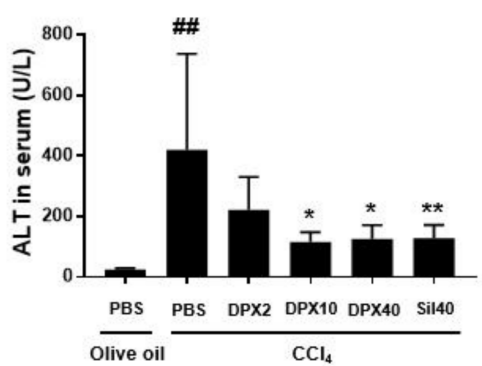

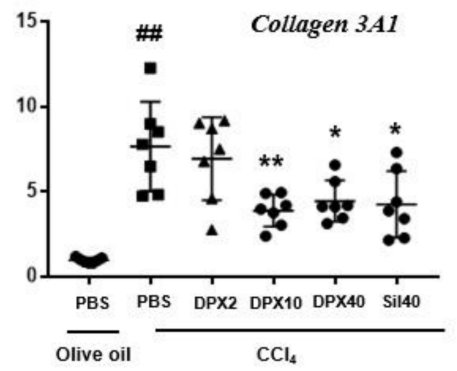

D

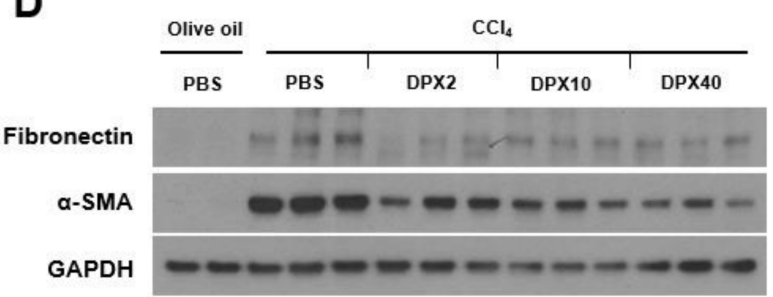

Figure 4. Cont. 
E

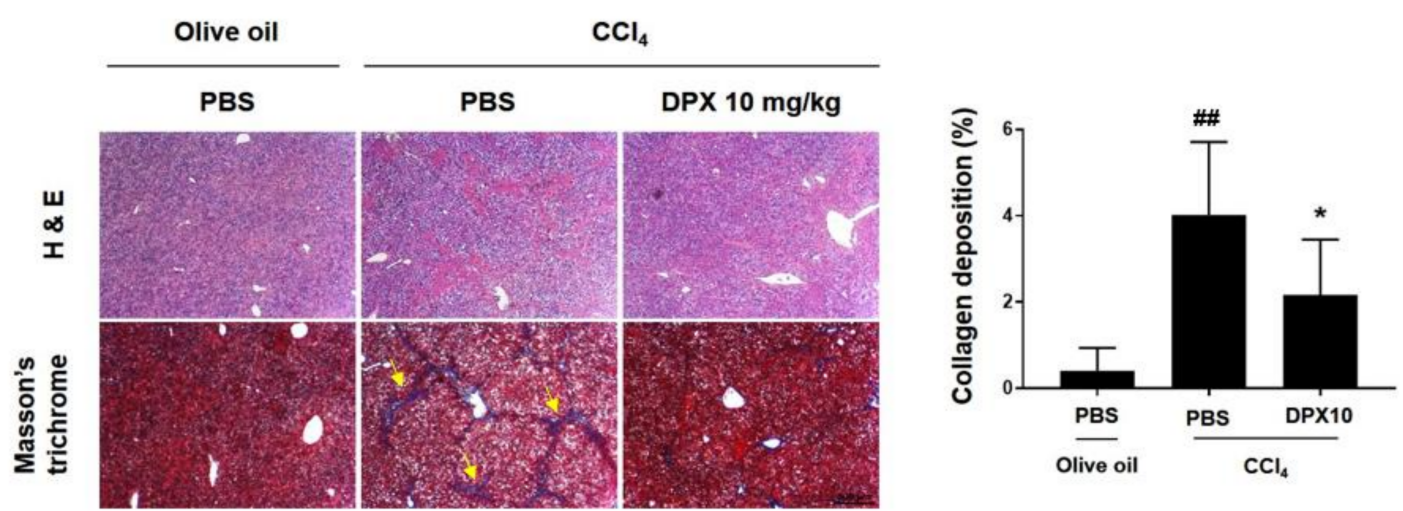

Figure 4. Dendropanoxide (DPX) attenuates carbon tetrachloride-induced chronic hepatic fibrosis. (A) Mice were treated with PBS or DPX $(2,10,40 \mathrm{mg} / \mathrm{kg})$ or silymarin (Sil, $40 \mathrm{mg} / \mathrm{kg}$ ) for three weeks, after three weeks of olive oil or carbon tetrachloride $(2 \mathrm{~mL} / \mathrm{kg})$ treatment. (B) Serum aspartate aminotransferase (AST) and alanine transaminase (ALT) levels were measured. (C) Expression of $\alpha-S M A$, Col1A1, and Col3A1 was measured by qRT-PCR analysis. (D) Protein expression of fibronectin and $\alpha$-SMA in the livers of mice from each group was analyzed by Western blotting. GAPDH was used as a loading control. (E) Representative histological images of livers after H\&E and Masson's trichrome staining (yellow arrow: collagen deposition; scale bar $=500 \mu \mathrm{m}$ ). Values represent mean $\pm \operatorname{SD}(n=7)$. \#\# $p<0.01$ compared with control, ${ }^{*} p<0.05$, ${ }^{* *} p<0.01$ compared with carbon tetrachloride treatment group.

Table 2. Body and liver weight in olive oil + olive oil-, olive oil + carbon tetrachloride-, DPX + carbon tetrachloride-, and silymarin + carbon tetrachloride-treated groups.

\begin{tabular}{|c|c|c|c|c|c|c|}
\hline & $\begin{array}{l}\text { Olive Oil + } \\
\text { Olive Oil }\end{array}$ & $\begin{array}{c}\text { Olive oil + } \\
\text { Carbon } \\
\text { Tetrachloride }\end{array}$ & $\begin{array}{c}\text { DPX 2+ } \\
\text { Carbon } \\
\text { Tetrachloride }\end{array}$ & $\begin{array}{c}\text { DPX } 10+ \\
\text { Carbon } \\
\text { Tetrachloride }\end{array}$ & $\begin{array}{c}\text { DPX } 40+ \\
\text { Carbon } \\
\text { Tetrachloride }\end{array}$ & $\begin{array}{c}\text { Silymarin } 40+ \\
\text { Carbon } \\
\text { Tetrachloride }\end{array}$ \\
\hline $\begin{array}{l}\text { Initial body } \\
\text { weight }(g)\end{array}$ & $22.78 \pm 0.50$ & $23.33 \pm 1.20$ & $23.29 \pm 0.69$ & $22.8 \pm 1.06$ & $22.0 \pm 0.58$ & $22.93 \pm 1.52$ \\
\hline $\begin{array}{l}\text { Final body } \\
\text { weight }(\mathrm{g})\end{array}$ & $26.34 \pm 0.80$ & $25.91 \pm 1.27$ & $25.31 \pm 0.69$ & $24.36 \pm 1.11$ & $23.59 \pm 0.92$ & $24.81 \pm 0.98$ \\
\hline Liver weight (g) & $1.35 \pm 0.10$ & $1.6 \pm 0.17$ & $1.51 \pm 0.09$ & $1.44 \pm 0.15$ & $1.17 \pm 0.08$ & $1.30 \pm 0.12$ \\
\hline $\begin{array}{c}\text { Liver weight } \\
\text { /body weight }(\times 100)\end{array}$ & $5.11 \pm 0.34$ & $6.18 \pm 0.49 \# \#$ & $5.98 \pm 0.18$ & $5.92 \pm 0.46$ & $4.95 \pm 0.32 * *$ & $5.24 \pm 0.34 * *$ \\
\hline
\end{tabular}

Mean + SD are shown ( $n=7)$. DPX: dendropanoxide, DPX 2: DPX $2 \mathrm{mg} / \mathrm{kg}$, DPX 10: DPX $10 \mathrm{mg} / \mathrm{kg}, \mathrm{DPX} 40$ DPX $40 \mathrm{mg} / \mathrm{kg}$, Silymarin 40: silymarin $40 \mathrm{mg} / \mathrm{kg}$. \#\# $p<0.01$ compared with control, ${ }^{* *} p<0.01$ compared with olive oil + carbon tetrachloride-treated group.

\subsection{Anti-Fibrotic Effects of DPX by Inhibiting Autophagy Inhibition}

As a result of a DPX mechanism study associated with HSC activation, we found that DPX inhibited autophagosome formation; HSC activation did not occur through the SMAD or MAPK pathway (data not shown). TGF- $\beta 1$ increased expression of an autophagosome marker (LC3B-II) and decreased p62 expression; however, DPX treatment significantly decreased LC3B-II and increased p62 expression (Figure 5A). DPX also inhibited LC3B-II mRNA expression (Figure 5B). An autophagy flux assay was performed to determine whether reduction in LC3B-II was caused by suppression of autophagosome formation or lysosome degradation. The result of co-treatment with chloroquine, an autophagy inhibitor that prevents fusion of autophagosome and lysosome, indicated that DPX inhibited autophagosome formation. DPX decreased LC3B-II expression in cells treated with or without chloroquine (Figure 5C). 
A

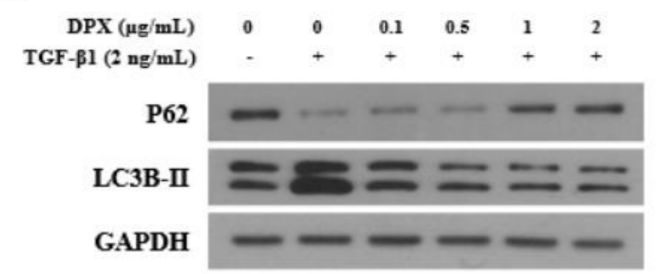

B

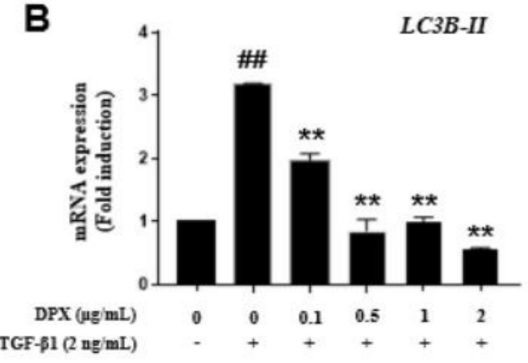

C

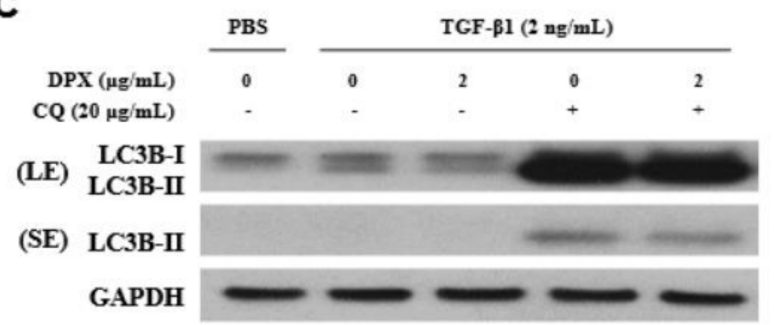

Figure 5. Dendropanoxide (DPX) inhibits HSC activation through autophagy inhibition. (A) Protein levels of autophagy markers (p62 and LC3B) were measured by Western blotting in LX-2 cells. (B) Relative LC3B-II mRNA expression was analyzed by qRT-PCR analysis. (C) Effects of autophagy inhibitor (chloroquine, CQ) on DPX activity were analyzed by Western blotting. GAPDH was used as a loading control. LE: long exposure, SE: short exposure. Each experiment was repeated three times, and values represent mean $\pm \mathrm{SD}$. \#\# $p<0.01$ compared with control, ${ }^{* *} p<0.01$ compared with the TGF- $\beta 1$ treatment group.

\section{Discussion}

DPM is a native plant in Korea and has been used as an anti-oxidant, anti-inflammatory, and anti-cancer agent [23]. In this study, we isolated DPX from the ethanolic extract of DPM and showed its anti-fibrotic potential in hepatic fibrosis. DPX strongly suppressed HSC activation and ECM accumulation in activated LX-2 cells and in a chronic hepatic fibrosis mouse model. Our result reveals that DPX has anti-fibrotic effects on the liver by inhibiting autophagosome formation in HSCs.

Hepatic fibrosis is characterized by excessive ECM accumulation, which is a result of chronic liver injury and wound repair processes [24]. HSCs are activated after liver injury and transdifferentiate to myofibroblast-like cells that can secrete inflammatory mediators and ECM components [5,25]. In our experiment, we used TGF- $\beta 1$, one of the most wellstudied cytokines, to activate HSCs [26]. TGF- $\beta 1$ significantly increased expression of HSC activation markers ( $\alpha$-SMA and collagen) in immortalized LX-2 HSC cells. DPX reversed HSC activation in LX-2 cells at $2 \mu \mathrm{g} / \mathrm{mL}$ without cytotoxicity. The anti-fibrotic effect of DPX was evaluated in a chronic hepatic fibrosis mouse model induced by carbon tetrachloride intraperitoneal (I.P.) injection. In previous results, protective effects of an aqueous extract of DPM against hepatic fibrosis were reported in a thioacetamide-induced hepatic fibrosis rat model. The major components in DPM aqueous extract were reported to be syringin, chlorogenic acid, rutin, and quercetin [21]; however, DPX was found to be a major component in the dichloromethane fraction of DPM ethanolic extract. Carbon tetrachloride induces liver toxicity [27]. Cytochrome P450 enzymes metabolize carbon tetrachloride to a trichloroethane radical; these can react with nucleic acids, proteins, and lipids and result in hepatic damage and lead to inflammation, fibrosis, cirrhosis, and carcinoma associated with HSC activation [27-29]. In our experiment, DPX administration was started in the early stage of fibrosis after three weeks of carbon tetrachloride injections and continued for three weeks along with carbon tetrachloride administration [30]. Liver damage markers (serum AST and ALT) and fibrotic markers were significantly downregulated by DPX treatment, and its effects were comparable to those of silymarin, the hepatoprotective positive control (Figure 4). 
In exploring the molecular mechanism of HSC activation, we found that DPX strongly inhibited autophagy during HSC activation. DPX induces autophagy through Erk1/2 activation in osteosarcoma cells [31]. However, in our experiment, DPX did not change the expression of Erk1/2; instead, autophagy inhibition by DPX was observed in activated HSCs (Figure 5A). Autophagy is a catabolic intracellular pathway that degrades and recycles intracellular organelles using lysosomes through the endocytic pathway [32]. Autophagic flux is increased during HSC activation, and inhibition of autophagy reverses HSC activation and hepatic fibrosis [33,34]. In this study, LC3-II expression was noticeably increased in activated HSCs, and DPX significantly suppressed LC3B-II expression and increased p62 expression (Figure 5A). p62 is a selective autophagy substrate inversely correlated with autophagic activity, because it is degraded by autophagy [35]. Light chain 3 (LC3) is a marker for autophagosome biogenesis, especially LC3-II. LC3-II is converted from LC3-I and is localized in both the outer and inner membranes of autophagosomes; in contrast, LC3-I is only localized in the cytosol. Therefore, LC3-II correlates well with autophagosome formation and is a major marker of autophagy [36,37]. However, enhanced autophagy can also decrease LC3-II through rapid autolysosomal degradation [38]. Because difficulty arises in fully explaining autophagy flux by the amount of LC3-II at a certain time point, evaluating LC3-II expression in the presence and absence of lysosomal inhibitors is important. These inhibitors block autophagosome-lysosome fusion, the last stage of autophagy. We performed an autophagy flux assay using chloroquine as a lysosome inhibitor [39]. DPX and chloroquine co-treatment inhibited autophagy by suppressing autophagosome formation.

\section{Conclusions}

To the best of our knowledge, this is the first study to show the anti-fibrotic effects of DPX in hepatic fibrosis. Hepatic fibrosis is a common chronic disease for which effective therapies are needed. Herein, we revealed that the ethanolic extract of DPM inhibits HSC activation. DPX isolated from DPM ethanolic extract reduced expression of HSC activation markers. DPX also significantly lowered serum AST and ALT levels, HSC activation markers, and collagen deposition in the carbon tetrachloride-induced chronic hepatic fibrosis mouse model. Its anti-fibrotic effect was similar to that of silymarin. Furthermore, we showed that DPX inhibited HSC activation through autophagy inhibition by measuring LC3B-II and p62 expression levels. These results support treatment potential for DPX in hepatic fibrosis by inhibiting HSC activation associated with the autophagy pathway (Figure 6).

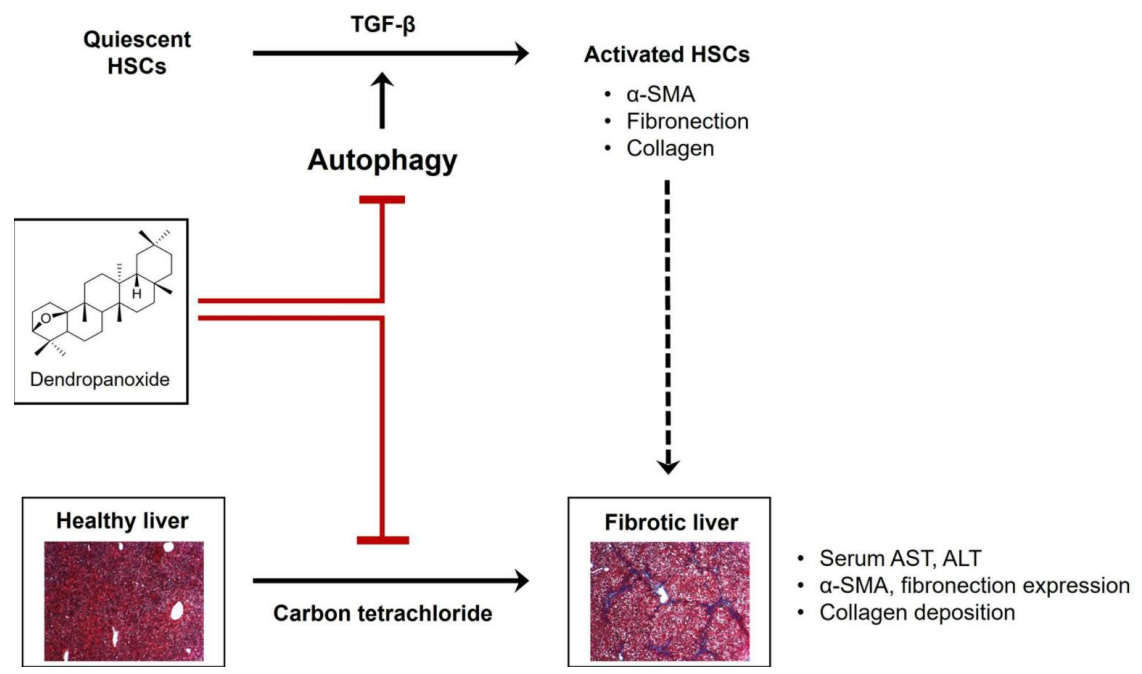

Figure 6. Schematic illustration of the ameliorative effect of dendropanoxide in chronic hepatic fibrosis. Dendropanoxide ameliorates chronic hepatic fibrosis by inhibiting activation of hepatic stellate cells through autophagy inhibition. 
Supplementary Materials: The following are available online at https:/ / www.mdpi.com/article/ 10.3390/nu14010098/s1, Figure S1: Extraction and isolation scheme for dendropanoxide from the aerial parts of Dendropanax morbifera. (A) Extraction and partition scheme for the aerial parts of D. morbifera. (B) Scheme for the isolation of dendropanoxide from the dichloromethane fraction, Figure S2: ${ }^{1} \mathrm{H}$ NMR spectrum of dendropanoxide $\left(\mathrm{CDCl}_{3}, 500 \mathrm{MHz}\right)$, Figure $\mathrm{S} 3:{ }^{13} \mathrm{C} \mathrm{NMR}$ spectrum of dendropanoxide $\left(\mathrm{CDCl}_{3}, 125 \mathrm{MHz}\right)$, Figure S4. GC/EIMS spectrum of dendropanoxide.

Author Contributions: Conceptualization, Y.-J.P. and K.-H.C.; methodology, D.-M.K.; validation, H.B.C. and M.-H.J.; formal analysis, S.-H.K. and H.-R.K.; investigation, D.-M.K. and J.-H.K.; resources, J.-H.K.; writing-original draft preparation, Y.-J.P. and D.-M.K.; writing-review and editing, H.-R.K. and K.-H.C.; visualization, M.-H.J.; project administration, K.-H.C.; funding acquisition, Y.-J.P. All authors have read and agreed to the published version of the manuscript.

Funding: This research was supported by Kyungsung University Research Grants in 2021.

Institutional Review Board Statement: The study was conducted according to the guidelines of the National Institutes of Health, and animal experiments were approved by the Sungkyunkwan University Animal Care Committee (SKKUIACUC2018-10-44-2).

Informed Consent Statement: Not applicable.

Data Availability Statement: The data presented in this study are available from the corresponding author on request.

Conflicts of Interest: The authors declare no conflict of interest.

\section{References}

1. Harris, R.; Harman, D.J.; Card, T.R.; Aithal, G.P.; Guha, I.N. Prevalence of clinically significant liver disease within the general population, as defined by non-invasive markers of liver fibrosis: A systematic review. Lancet Gastroenterol. Hepatol. 2017, 2, 288-297. [CrossRef]

2. Povero, D.; Busletta, C.; Novo, E.; di Bonzo, L.V.; Cannito, S.; Paternostro, C.; Parola, M. Liver fibrosis: A dynamic and potentially reversible process. Histol. Histopathol. 2010, 25, 1075-1091.

3. Moreira, R.K. Hepatic stellate cells and liver fibrosis. Arch. Pathol. Lab. Med. 2007, 131, 1728-1734. [CrossRef] [PubMed]

4. Zhang, C.Y.; Yuan, W.G.; He, P.; Lei, J.H.; Wang, C.X. Liver fibrosis and hepatic stellate cells: Etiology, pathological hallmarks and therapeutic targets. World J. Gastroenterol. 2016, 22, 10512-10522. [CrossRef] [PubMed]

5. Tsuchida, T.; Friedman, S.L. Mechanisms of hepatic stellate cell activation. Nat. Rev. Gastroenterol. Hepatol. $2017,14,397-411$. [CrossRef]

6. Schmitt-Graff, A.; Kruger, S.; Bochard, F.; Gabbiani, G.; Denk, H. Modulation of alpha smooth muscle actin and desmin expression in perisinusoidal cells of normal and diseased human livers. Am. J. Pathol. 1991, 138, 1233-1242. [PubMed]

7. Nouchi, T.; Tanaka, Y.; Tsukada, T.; Sato, C.; Marumo, F. Appearance of alpha-smooth-muscle-actin-positive cells in hepatic fibrosis. Liver 1991, 11, 100-105. [CrossRef]

8. Yamaoka, K.; Nouchi, T.; Marumo, F.; Sato, C. Alpha-smooth-muscle actin expression in normal and fibrotic human livers. Dig. Dis. Sci. 1993, 38, 1473-1479. [CrossRef] [PubMed]

9. Guido, M.; Rugge, M.; Chemello, L.; Leandro, G.; Fattovich, G.; Giustina, G.; Cassaro, M.; Alberti, A. Liver stellate cells in chronic viral hepatitis: The effect of interferon therapy. J. Hepatol. 1996, 24, 301-307. [CrossRef]

10. Higashi, T.; Friedman, S.L.; Hoshida, Y. Hepatic stellate cells as key target in liver fibrosis. Adv. Drug Deliv. Rev. 2017, 121, 27-42 [CrossRef]

11. Cursio, R.; Colosetti, P.; Codogno, P.; Cuervo, A.M.; Shen, H.M. The role of autophagy in liver diseases: Mechanisms and potential therapeutic targets. BioMed Res. Int. 2015, 2015, 480508. [CrossRef] [PubMed]

12. Mao, Y.Q.; Fan, X.M. Autophagy: A new therapeutic target for liver fibrosis. World J. Hepatol. 2015, 7, 1982-1986. [CrossRef] [PubMed]

13. Choi, H.J.; Park, D.H.; Song, S.H.; Yoon, I.S.; Cho, S.S. Development and Validation of a HPLC-UV Method for Extraction Optimization and Biological Evaluation of Hot-Water and Ethanolic Extracts of Dendropanax morbifera Leaves. Molecules 2018, 23, 650. [CrossRef]

14. Kim, W.; Kim, D.W.; Yoo, D.Y.; Jung, H.Y.; Nam, S.M.; Kim, J.W.; Hong, S.M.; Kim, D.W.; Choi, J.H.; Moon, S.M.; et al. Dendropanax morbifera Leveille extract facilitates cadmium excretion and prevents oxidative damage in the hippocampus by increasing antioxidant levels in cadmium-exposed rats. BMC Complement. Altern. Med. 2014, 14, 428. [CrossRef] [PubMed]

15. Kim, E.S.; Lee, J.S.; Akram, M.; Kim, K.A.; Shin, Y.J.; Yu, J.H.; Bae, O.N. Protective activity of Dendropanax morbifera against cisplatin-induced acute kidney injury. Kidney Blood Press Res. 2015, 40, 1-12. [CrossRef] [PubMed] 
16. Akram, M.; Kim, K.A.; Kim, E.S.; Syed, A.S.; Kim, C.Y.; Lee, J.S.; Bae, O.N. Potent Anti-inflammatory and Analgesic Actions of the Chloroform Extract of Dendropanax morbifera Mediated by the Nrf2/HO-1 Pathway. Biol. Pharm. Bull. 2016, 39, 728-736. [CrossRef]

17. Kim, W.; Yim, H.S.; Yoo, D.Y.; Jung, H.Y.; Kim, J.W.; Choi, J.H.; Yoon, Y.S.; Kim, D.W.; Hwang, I.K. Dendropanax morbifera Leveille extract ameliorates cadmium-induced impairment in memory and hippocampal neurogenesis in rats. BMC Complement. Altern. Med. 2016, 16, 452. [CrossRef] [PubMed]

18. Heo, M.-G.; Byun, J.-H.; Kim, J.; Choung, S.-Y. Treatment of Dendropanax morbifera leaves extract improves diabetic phenotype and inhibits diabetes induced retinal degeneration in $\mathrm{db} / \mathrm{db}$ mice. J. Funct. Foods 2018, 46, 136-146. [CrossRef]

19. Moon, H.I. Antidiabetic effects of dendropanoxide from leaves of Dendropanax morbifera Leveille in normal and streptozotocininduced diabetic rats. Hum. Exp. Toxicol. 2011, 30, 870-875. [CrossRef]

20. Chung, I.M.; Kim, M.Y.; Park, W.H.; Moon, H.I. Antiatherogenic activity of Dendropanax morbifera essential oil in rats. Pharmazie 2009, 64, 547-549.

21. Yang, H.Y.; Kim, K.S.; Lee, Y.H.; Park, J.H.; Kim, J.H.; Lee, S.Y.; Kim, Y.M.; Kim, I.S.; Kacew, S.; Lee, B.M.; et al. Dendropanax morbifera Ameliorates Thioacetamide-Induced Hepatic Fibrosis via TGF-beta1/Smads Pathways. Int. J. Biol. Sci. 2019, 15, 800-811. [CrossRef]

22. Tori, M.; Matsuda, R.; Sono, M.; Asakawa, Y. 13C NMR assignment of dammarane triterpenes and dendropanoxide: Application of 2D long-range 13C-1H correlation spectra. Magn. Reson. Chem. 1988, 26, 581-590. [CrossRef]

23. Kim, M.; Park, Y.J.; Lim, H.S.; Lee, H.H.; Kim, T.H.; Lee, B. The Clinical Effects of Dendropanax Morbifera on Postmenopausal Symptoms: Review Article. J. Menopausal. Med. 2017, 23, 146-155. [CrossRef]

24. Baiocchini, A.; Montaldo, C.; Conigliaro, A.; Grimaldi, A.; Correani, V.; Mura, F.; Ciccosanti, F.; Rotiroti, N.; Brenna, A.; Montalbano, M.; et al. Extracellular Matrix Molecular Remodeling in Human Liver Fibrosis Evolution. PLoS ONE 2016, 11, e0151736. [CrossRef]

25. Puche, J.E.; Saiman, Y.; Friedman, S.L. Hepatic stellate cells and liver fibrosis. Compr. Physiol. 2013, 3, 1473-1492. [PubMed]

26. Dewidar, B.; Soukupova, J.; Fabregat, I.; Dooley, S. TGF- $\beta$ in Hepatic Stellate Cell Activation and Liver Fibrogenesis: Updated. Curr. Pathobiol. Rep. 2015, 3, 291-305. [CrossRef]

27. Scholten, D.; Trebicka, J.; Liedtke, C.; Weiskirchen, R. The carbon tetrachloride model in mice. Lab. Anim 2015, 49, 4-11. [CrossRef] [PubMed]

28. Slater, T.F.; Cheeseman, K.H.; Ingold, K.U. Carbon tetrachloride toxicity as a model for studying free-radical mediated liver injury Philos. Trans. R. Soc. Lond. B Biol. Sci. 1985, 311, 633-645. [PubMed]

29. Kim, K.Y.; Choi, I.; Kim, S.S. Progression of hepatic stellate cell activation is associated with the level of oxidative stress rather than cytokines during CCl4-induced fibrogenesis. Mol. Cells 2000, 10, 289-300.

30. Nevzorova, Y.A.; Bangen, J.M.; Hu, W.; Haas, U.; Weiskirchen, R.; Gassler, N.; Huss, S.; Tacke, F.; Sicinski, P.; Trautwein, C.; et al. Cyclin E1 controls proliferation of hepatic stellate cells and is essential for liver fibrogenesis in mice. Hepatology 2012, 56, 1140-1149. [CrossRef]

31. Lee, J.W.; Kim, K.S.; An, H.K.; Kim, C.H.; Moon, H.I.; Lee, Y.C. Dendropanoxide induces autophagy through ERK1/2 activation in MG-63 human osteosarcoma cells and autophagy inhibition enhances dendropanoxide-induced apoptosis. PLoS ONE 2013, $8, \mathrm{e} 83611$.

32. Settembre, C.; Fraldi, A.; Medina, D.L.; Ballabio, A. Signals from the lysosome: A control centre for cellular clearance and energy metabolism. Nat. Rev. Mol. Cell Biol. 2013, 14, 283-296. [CrossRef] [PubMed]

33. Hernandez-Gea, V.; Ghiassi-Nejad, Z.; Rozenfeld, R.; Gordon, R.; Fiel, M.I.; Yue, Z.; Czaja, M.J.; Friedman, S.L. Autophagy releases lipid that promotes fibrogenesis by activated hepatic stellate cells in mice and in human tissues. Gastroenterology 2012, 142, 938-946. [CrossRef] [PubMed]

34. Thoen, L.F.; Guimaraes, E.L.; Dolle, L.; Mannaerts, I.; Najimi, M.; Sokal, E.; van Grunsven, L.A. A role for autophagy during hepatic stellate cell activation. J. Hepatol. 2011, 55, 1353-1360. [CrossRef] [PubMed]

35. Bjorkoy, G.; Lamark, T.; Brech, A.; Outzen, H.; Perander, M.; Overvatn, A.; Stenmark, H.; Johansen, T. p62/SQSTM1 forms protein aggregates degraded by autophagy and has a protective effect on huntingtin-induced cell death. J. Cell Biol. 2005, 171, 603-614. [CrossRef] [PubMed]

36. Kabeya, Y.; Mizushima, N.; Ueno, T.; Yamamoto, A.; Kirisako, T.; Noda, T.; Kominami, E.; Ohsumi, Y.; Yoshimori, T. LC3, a mammalian homologue of yeast Apg8p, is localized in autophagosome membranes after processing. EMBO J. 2000, 19, 5720-5728. [CrossRef] [PubMed]

37. Mizushima, N.; Yoshimori, T.; Levine, B. Methods in mammalian autophagy research. Cell 2010, 140, 313-326. [CrossRef]

38. Yoshii, S.R.; Mizushima, N. Monitoring and Measuring Autophagy. Int. J. Mol. Sci. 2017, 18, 1865. [CrossRef]

39. Mauthe, M.; Orhon, I.; Rocchi, C.; Zhou, X.; Luhr, M.; Hijlkema, K.J.; Coppes, R.P.; Engedal, N.; Mari, M.; Reggiori, F. Chloroquine inhibits autophagic flux by decreasing autophagosome-lysosome fusion. Autophagy 2018, 14, 1435-1455. [CrossRef] 